\title{
L-Asparaginase Production using Solid-state Fermentation by an Endophytic Talaromyces pinophilus Isolated from Rhizomes of Curcuma amada
}

\author{
Prajna Rao Krishnapura and Prasanna D. Belur* (D) \\ Department of Chemical Engineering, National Institute of Technology Karnataka (N.I.T.K.), Surathkal, Srinivasnagar, \\ Mangaluru - 575 025, Karnataka, India.
}

\begin{abstract}
In recent times, exploration of endophytes for L-asparaginase production is gradually gaining momentum. This work deals with studies on the production of L-asparaginase from Talaromyces pinophilus, an endophytic fungus isolated from the rhizomes of Curcuma amada. L-asparaginase production was carried out by Submerged Fermentation (SmF) followed by Solid-state Fermentation (SSF). A liquid medium was designed and optimized using Plackett-Burman Design and Response Surface Methodology (RSM), under SmF. Additionally, optimal concentrations of various metal salts were incorporated in the optimized liquid medium, by one-factor-at-a-time experiments. To further enhance L-asparaginase production, SSF was carried out using Polyurethane Foam (PUF) as inert support impregnated with the optimized liquid medium. Effects of PUF cube volume, mass of PUF, moisture content, initial medium $\mathrm{pH}$, and incubation temperature on the enzyme production in SSF were optimized by one-factor-at-a-time approach.L-asparaginase production enhanced from $80.8 \mathrm{U} / \mathrm{mL}$ in the unoptimized medium to $94.4 \mathrm{U} / \mathrm{mL}$ in the optimized medium under SmF. Enzyme production further increased to $120.3 \mathrm{U} / \mathrm{mL}$ under SSF by using PUF soaked in the optimized liquid medium. This study highlights the benefits of carrying out SSF with PUF, using the same liquid medium optimized for SmF - a novel approach to enhance the enzyme yield (in our case an increase of about $27 \%$ was observed). To the best of our knowledge, this is the first report on the production of L-asparaginase by both SmF and SSF, from an endophyte Talaromyces pinophilus isolated from the rhizomes of Curcuma amada.
\end{abstract}

Keywords: L-asparaginase, Plackett-Burman Design, Polyurethane Foam (PUF), Response Surface Methodology (RSM), Submerged fermentation (SmF), Solid-state fermentation (SSF)

*Correspondence: prsnbhat@gmail.com

(Received: May 16, 2019; accepted: January 22, 2020)

Citation: Prajna Rao Krishnapura and Prasanna D. Belur, L-Asparaginase Production using Solid-state Fermentation by an Endophytic Talaromyces pinophilus Isolated from Rhizomes of Curcuma amada, J. Pure Appl. Microbiol., 2020; 14(1):307-318. https://doi.org/10.22207/JPAM.14.1.32

(C) The Author(s) 2020. Open Access. This article is distributed under the terms of the Creative Commons Attribution 4.0 International License which permits unrestricted use, sharing, distribution, and reproduction in any medium, provided you give appropriate credit to the original author(s) and the source, provide a link to the Creative Commons license, and indicate if changes were made. 


\section{INTRODUCTION}

L-asparaginase is a prominent enzyme, which is used in the treatment of Acute Lymphoblastic Leukaemia (ALL), a prevalent form of paediatric cancer ${ }^{1}$. Another of the applications of the enzyme is in food industry, where it is used to mitigate the formation of acrylamide in food products that require processing at temperatures above $100^{\circ} \mathrm{C}^{2}$. Fungal L-asparaginases are considered safe by Joint FAO/WHO Expert Committee on Food Additives-2007 and are used as food additives ${ }^{3}$. L-asparaginase holds potential for more extensive applications in the treatment of other diseases apart from cancer. One of such applicability is in the treatment of infectious diseases caused by Streptococcus pyogenes, Staphylococcus aureus, Listeria monocytogenes and Clostridium botulinum ${ }^{4}$. L-asparaginases from Escherichia coli and Erwinia chrysanthemi are commercially available for the treatment of ALL. Although effective, their therapeutic utilization is hindered by complications involving hypersensitivity and several other toxic side effects $^{5,6}$. For utilization in the food industry, only a couple of L-asparaginases are available with the brand names Acrylaway and Preventase. These limitations advocate the exploration for newer and high yielding microbial sources of L-asparaginase ${ }^{7}$. Endophytes in particular are gaining importance as potential sources of L-asparaginases ${ }^{8}$.

The commercial demand for L-asparaginase lays stress on the need for optimized fermentation processes for obtaining high productivity. Improvement of productivity can be achieved through optimization of the nutritional and process parameters. L-asparaginase is largely produced by Submerged fermentation (SmF). Solid-state fermentation (SSF) for L-asparaginase production by fungi has mainly involved the usage of agricultural wastes ${ }^{9-11}$. However, SSF processes utilizing agricultural by-products or non-inert raw materials have disadvantages such as change in the medium characteristics and support degradation over time, difficulties in downstream processing of the products ${ }^{12}$ and in biomass estimation ${ }^{13}$. These drawbacks could be overcome by the use of inert supports such as Polyurethane Foam (PUF). Usage of PUF in SSF for enzyme production by fungi imparts advantages such as homogeneous aeration ${ }^{13,14}$, and a possibility of running successive cycles of fermentation by reuse of the fungi adsorbed on PUF ${ }^{15}$.

The current work focuses on the enhancement of L-asparaginase production from an endophytic fungus Talaromyces pinophilus, isolated from the rhizomes of Curcuma amada (Mango-ginger), by sequential media optimization. A liquid medium to improve L-asparaginase production was designed by optimization using Plackett-Burman Design (PBD) experiments and Response Surface Methodology (RSM), under SmF. Subsequently, various metal salts were incorporated into this liquid medium based on one-factor-at-a-time method. To further enhance L-asparaginase production, SSF was adopted using PUF impregnated with the previously optimized liquid medium, and the optimal values of various process parameters were determined using onefactor-at-a-time approach.

The technique of impregnation of PUF with defined liquid media has been found to improve the productivity of enzymes in SSF involving fungi ${ }^{13-15}$. In such SSF processes which incorporate PUF, optimization of the liquid media plays an important role. The use of a defined liquid medium enables controlling and monitoring of the SSF process, and also ensures the reproducibility of the process ${ }^{13,16}$.

\section{MATERIALS AND METHODS Microorganism}

Talaromyces pinophilus previously isolated in our laboratory from the rhizomes of Curcuma amada (Krishnapura et al., 2015b), was used for the fermentation studies. The ITS/5.8S rRNA gene sequencing of the organism was carried out at IMTECH, Chandigarh, India. The data was deposited in GenBank and was assigned the accession No. KJ372306. The culture was maintained on MCD agar media with the composition (g/L): Glucose, 2.0; L-asparagine, 10.0; $\mathrm{KH}_{2} \mathrm{PO}_{4}, 1.52 ; \mathrm{KCl}, 0.52 ; \mathrm{MgSO}_{4} .7 \mathrm{H}_{2} \mathrm{O}, 0.52$; $\mathrm{FeSO}_{4} \cdot 7 \mathrm{H}_{2} \mathrm{O}, 0.01$; agar, 18.0, and $\mathrm{pH} 6.5$.

\section{Determination of enzyme activity}

The enzyme extraction in all the smf experiments was carried out as mentioned by Krishnapura and Belur ${ }^{8}$. In SSF experiments, the PUF cubes, upon completion of fermentation, were washed with $50 \mathrm{ml}$ sterile distilled water and compressed to release the fermentation broth, 
which was filtered through whatman no. 2 filter paper. The filtrate was used as the crude enzyme for L-asparaginase assay. The enzyme activity of I-asparaginase was determined by measuring the amount of ammonia formed, using direct nesslerization method based on Imada et al. ${ }^{17}$. One unit of L-asparaginase is the amount of enzyme which liberates $1 \mu \mathrm{mol}$ of ammonia in 1 minute at $37^{\circ} \mathrm{C}$.

Designing the liquid media for L-asparaginase production

The designing of the liquid media was performed using PBD and RSM. All the experiments were carried out by SmF in $250 \mathrm{ml}$ conical flasks for 120 hours, at $28^{\circ} \mathrm{C}$, with an agitation rate of 120 $\mathrm{rpm}$, and an initial medium $\mathrm{pH}$ of 6.5. A 21-day old mycelial mat of Talaromyces pinophilus, of $5 \mathrm{~mm}$ diameter, grown on MCD agar medium was used as the inoculum. The above mentioned parameters had been optimized previously by one-factor-at-atime approach (results not presented here).

\section{Plackett-Burman design (PBD)}

PBD, a statistical approach was opted to choose the significant factors that influence maximum L-asparaginase production. The PBD matrix was created and the results were analyzed using Minitab software (Trial version 16.2.2, Minitab ${ }^{\circledR}$ Inc. 2010, USA). In the present investigation, 12 experimental trials were conducted with 11 factors -8 variables and 3 dummy variables. Each of the eight variables were tested at two levels, a high (+1) and a low (-1) level i.e., at two different nutrient concentrations (Table
1). Temperature $\left(28^{\circ} \mathrm{C}\right), \mathrm{pH}(6.5)$ and inoculum age (21 days old culture) were assigned the role of dummy variables and were maintained at constant values. All the experiments were carried out in duplicates and the average of the L-asparaginase activity was considered as the response.

Response surface methodology (RSM)

RSM was used to elicit the optimal concentrations of the most significant independent variables screened using the $P B D$, to maximize L-asparaginase production. A total of 20 trials were run with three factors at five discrete levels $(-\alpha,-1,0,+1,+\alpha)$ in a Central Composite Design (CCD) (Table 2). L-asparaginase production (U/ $\mathrm{mL}$ ) was taken as the response. Minitab software (Trial version 16.2.2, Minitab $^{\circledR}$ Inc. 2010, USA) was used for multiple regression analysis of the experimental data and to construct the response surface plots. The response values in each trial were the average of the duplicates. The data obtained from RSM on L-asparaginase production were subjected to analysis of variance (ANOVA). The relationship between the variables and their effect on the response was determined by fitting a second order polynomial equation ${ }^{16}$ to the data obtained:

$$
Y=\beta o+\sum i \beta i X i+\sum i i \beta i i X i i 2+\sum i j \beta i j X i X j
$$

Where, $Y$ is the predicted response, $X i$ and $X j$ are independent variables, $\beta$ o the intercept coefficient, $\beta i$ the linear effect coefficient, $\beta i i$ the squared effect coefficient, and $\beta \mathrm{ij}$ is the coefficient of the interaction effect. The optimum levels of different factors for maximum enzyme production

Table 1. Factors and their binary numerical settings in PBD for L-asparaginase production by SmF

\begin{tabular}{|c|c|c|c|c|}
\hline \multirow[t]{2}{*}{ Code } & \multirow[t]{2}{*}{ Factors } & & \multicolumn{2}{|c|}{ Range $(\% \mathrm{w} / \mathrm{v})$} \\
\hline & & & High (+1) & $\operatorname{Low}(-1)$ \\
\hline A & Carbon sources & Glucose & 0.5 & 1.5 \\
\hline B & & Sucrose & 0.5 & 1.5 \\
\hline C & & Starch & 0.5 & 1.5 \\
\hline D & Nitrogen sources (Organic) & Yeast extract & 0.5 & 1.5 \\
\hline $\mathrm{E}$ & & Peptone & 0.5 & 1.5 \\
\hline $\mathrm{F}$ & Nitrogen sources (Inorganic) & Ammonium sulphate & 0.5 & 1.5 \\
\hline G & & Sodium nitrate & 0.5 & 1.5 \\
\hline $\mathrm{H}$ & Inducer & L-asparagine & 0.5 & 1.5 \\
\hline I & Temperature & & $28^{\circ} \mathrm{C}$ & \\
\hline J & $\mathrm{pH}$ & & 6.5 & \\
\hline K & Inoculum age & & $\begin{array}{l}21 \text { days } \\
\text { old culture }\end{array}$ & \\
\hline
\end{tabular}


Table 2. Independent factors and their levels in the three-factor and five-level CCD

\begin{tabular}{lcccccc}
\hline \multirow{2}{*}{ Factor } & \multirow{2}{*}{ Code } & \multicolumn{5}{c}{ Values $(\% \mathrm{w} / \mathrm{v})$ of the factors at the coded levels } \\
\cline { 3 - 7 } & & $-1.68(-\alpha)$ & -1 & 0 & +1 & $+1.68(+\alpha)$ \\
\hline Starch & $\mathrm{A}$ & 0.1591 & 0.5 & 1 & 1.5 & 1.8409 \\
Yeast extract & $\mathrm{B}$ & 0.1591 & 0.5 & 1 & 1.5 & 1.8409 \\
L-asparagine & $\mathrm{C}$ & 0.1591 & 0.5 & 1 & 1.5 & 1.8409 \\
\hline
\end{tabular}

and the final response (yield) predicted by the model was validated by experimental trials in shake-flask trials.

\section{The effect of inorganic metal salts}

The effect of the following inorganic salts (concentration ranges in parenthesis) was studied by one-factor-at-a-time method, on the optimized liquid media: Potassium dihydrogen phosphate $(0.1-0.5 \% \mathrm{w} / \mathrm{v})$, Potassium chloride and Magnesium sulphate $(0.01-0.15 \% \mathrm{w} / \mathrm{v})$, Ferrous sulphate and Zinc sulphate $(0.001$ $0.005 \% \mathrm{w} / \mathrm{v})$. Control flasks were kept without the addition of the salts.

Solid-state fermentation (SSF)

SSF experiments were carried out with the optimized liquid media (Table 3) adsorbed onto PUF cubes. The density of the PUF used was determined as follows: the cubes were dried at $80^{\circ} \mathrm{C}$ for 24 hours and then cooled. The masses and dimensions of each of the cubes were recorded, and density was calculated.

Unless mentioned otherwise, fermentation was carried out in $250 \mathrm{~mL}$ sterile conical flasks with cotton plugs, with initial medium $\mathrm{pH}$ of 6.5 , at room temperature for 120 hours, after which the enzyme activity was determined. Prior to use, PUF was cut into cubes and washed with boiling water, followed by thorough rinsing with distilled water. The cubes were dried at room temperature and stored until use. The PUF cubes and the liquid media were autoclaved separately. The $\mathrm{pH}$ of the liquid media was set prior to autoclaving. $5 \mathrm{~mm}$-diameter mycelial mats of Talaromyces pinophilus from a 21-day old culture grown on MCD agar media was homogenized with $2 \mathrm{~mL}$ of sterile distilled water and was used as the inoculum for all the experiments. This inoculum was mixed with the liquid media and added to the PUF cubes in the conical flasks. All the experiments were carried out in duplicates, and the reported results are the average values.

Determination of optimal settings of process parameters for SSF by one-factor-at-a-time approach

The effect of moisture content on L-asparaginase production was studied with varying percentages $(10-100 \%$ by volume) of moisture. Water-holding capacity of the PUF cubes of different dimensions was calculated by measuring the maximum volume (in $\mathrm{mL}$ ) of water absorbed by the cubes without spillage ${ }^{11}$. This was considered as $100 \%$ of its water-holding capacity. Based on this, the volume of water required to maintain a desired percentage of moisture was calculated. To this volume of water, the media components were added, as per the composition mentioned in Table 3. The autoclaved liquid media was mixed with the inoculum, and added to $1.5 \mathrm{~g}$ of $8 \mathrm{~cm}^{3}$ PUF cubes (2-cm side) that were autoclaved separately.

The effect of initial medium $\mathrm{pH}$ in SSF, was studied by setting the $\mathrm{pH}$ of the liquid media to different values in the range 6 to 7.5 prior to autoclaving. This liquid media was added to $2 \mathrm{~g}$ of autoclaved PUF cubes. To study the effect of temperature, SSF was carried out at temperatures: $20^{\circ} \mathrm{C}, 25^{\circ} \mathrm{C}, 30^{\circ} \mathrm{C}$, and at room temperature. To study the effect of varying masses of PUF cubes, SSF trials were carried out with PUF cubes weighing in the range 1 to $4 \mathrm{~g}$. To study the effect of cube volume, $2 \mathrm{~g}$ of PUF cubes of volume $1 \mathrm{~cm} 3$ and $8 \mathrm{~cm} 3$ were used for the trials. Time course studies were carried out with SmF and with SSF to observe the pattern of the enzyme production. The L-asparaginase activity was measured every 24 hours. 


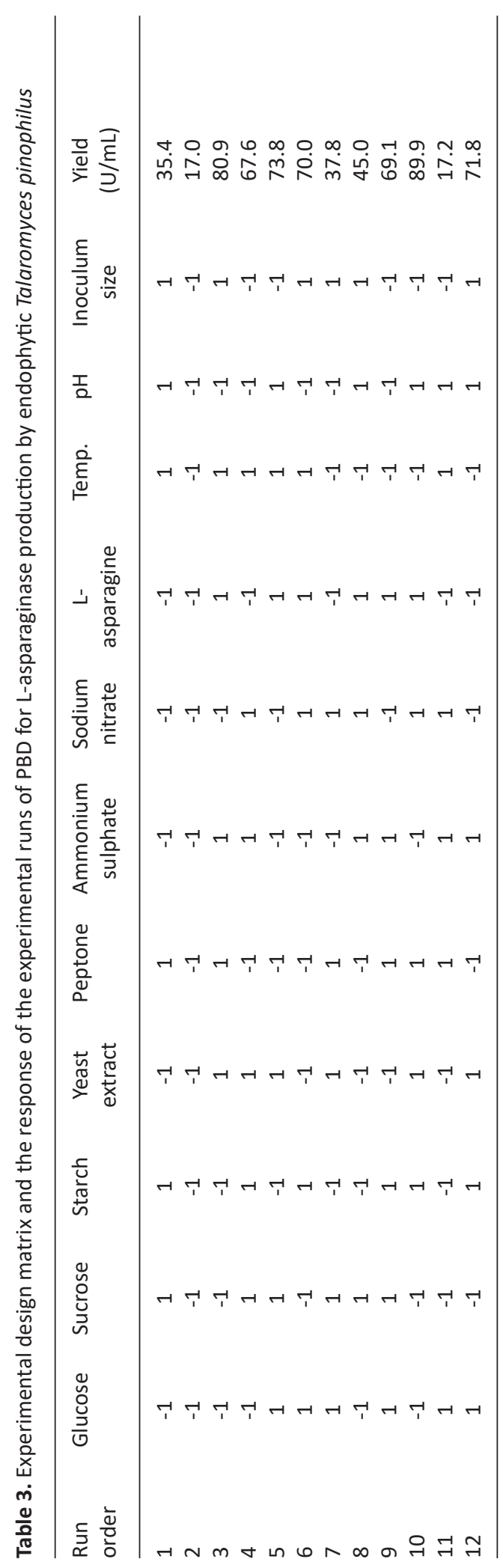

\section{RESULTS AND DISCUSSION}

The Plackett-Burman design experiments

The analysis of the data from the PBD experiments involved a first-order (main effects) model. L-asparaginase activity was observed in the range of $17.0 \mathrm{U} / \mathrm{mL}$ to $89.9 \mathrm{U} /$ $\mathrm{mL}$ in 12 experimental runs. One-way-ANOVA was carried out on the results obtained. The experimental design matrix and the response of the experimental runs are given in Table 3 and the response of each trial and its statistical analyses were given in Table 4.

Starch, yeast extract and L-asparagine were found to have significant positive effect on L-asparaginase production, as seen from the Pareto chart (Fig. 1).

\section{Response Surface Modeling}

The design matrix and the corresponding results of observed and predicted responses (production of L-asparaginase) are shown in Table 5.The results obtained from the CCD were fitted to a second order polynomial equation to express the mathematical relationship between L-asparaginase production and the medium components:

$$
Y=71.7653+9.04729 A+11.7083 B+
$$

$15.0405 C+3.11500 A B+3.48700 A C+8.80700 B C$ $-13.4297 A^{2}-14.1053 B^{2}-8.77179 C^{2}$

Where $Y$ is the predicted amount of L-asparaginase production, $A, B$ and $C$ are

Table 4. The main effect, co-efficient, $p$ - and F-values of the individual factors in PBD experiments for $\mathrm{L}$-asparaginase production by endophytic Talaromyces pinophilus

\begin{tabular}{lcccc}
\hline Term & $\begin{array}{c}\text { Main } \\
\text { effect }\end{array}$ & $\begin{array}{c}\text { Co- } \\
\text { efficient }\end{array}$ & $\begin{array}{c}\mathrm{p} \text { - } \\
\text { value }\end{array}$ & $\begin{array}{c}\mathrm{F} \\
\text { value }\end{array}$ \\
\hline Constant & & 56.358 & & \\
Glucose & 0.636 & 0.318 & 0.967 & 0.00 \\
Sucrose & -3.021 & -1.511 & 0.844 & 0.04 \\
Starch & 22.026 & 11.013 & 0.128 & 2.75 \\
Yeast extract & 28.005 & 14.003 & 0.043 & 5.36 \\
Peptone & -2.503 & -1.252 & 0.871 & 0.03 \\
Ammonium & 4.606 & 2.303 & 0.764 & 0.10 \\
sulphate & & & & \\
Sodium nitrate & -3.429 & -1.715 & 0.823 & 0.05 \\
L-asparagine & 30.328 & 15.164 & 0.025 & 6.93 \\
Temperature & 2.378 & 1.189 & 0.877 & 0.03 \\
pH & -1.546 & -0.773 & 0.920 & 0.01 \\
Inoculum size & 1.075 & 0.538 & 0.944 & 0.01 \\
& & & & \\
\hline
\end{tabular}


the coded terms for starch, yeast extract and L-asparagine respectively.

The analysis of variance of the quadratic regression model suggested that the model is statistically very significant as was evident from the Fisher's F-test (197.14) and p-value $(<0.001)$. The model's goodness of fit was checked by the coefficient of determination $\left(R^{2}\right)$. In this case,

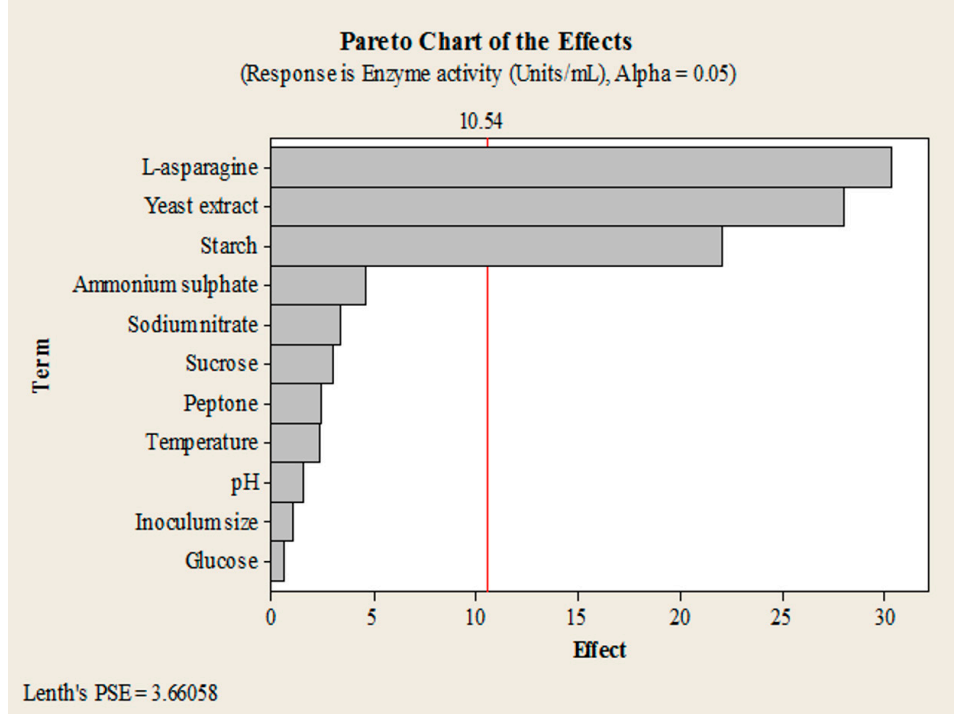

Fig. 1. Pareto chart of the effects of individual variables on L-asparaginase production by endophytic Talaromyces pinophilus in PBD experiments.

Table 5. The predicted and observed responses along with the CCD design matrix with factors in coded values for L-asparaginase production by endophytic Talaromyces pinophilus

\begin{tabular}{|c|c|c|c|c|c|}
\hline \multirow[t]{2}{*}{$\begin{array}{l}\text { Run } \\
\text { order }\end{array}$} & \multirow[t]{2}{*}{ Starch } & \multirow[t]{2}{*}{$\begin{array}{c}\text { Yeast } \\
\text { extract }\end{array}$} & \multirow[t]{2}{*}{$\begin{array}{c}\mathrm{L}- \\
\text { asparagine }\end{array}$} & \multicolumn{2}{|c|}{$\begin{array}{l}\text { Enzyme activity } \\
(\mathrm{U} / \mathrm{mL})\end{array}$} \\
\hline & & & & Actual & Predicted \\
\hline 1 & 0 & 0 & 1.68179 & 68.1658 & 72.2499 \\
\hline 2 & 0 & 0 & -1.68179 & 23.8927 & 21.6598 \\
\hline 3 & -1 & -1 & -1 & 14.8326 & 15.0713 \\
\hline 4 & 0 & 0 & 0 & 75.7060 & 71.7653 \\
\hline 5 & -1.68179 & 0.00000 & 0 & 17.5025 & 18.5646 \\
\hline 6 & 0 & 1.68179 & 0 & 50.0458 & 51.5605 \\
\hline 7 & 1 & -1 & 1 & 41.7054 & 39.4030 \\
\hline 8 & 0 & 0 & 0 & 71.4376 & 71.7653 \\
\hline 9 & 1 & 1 & -1 & 32.1364 & 31.9946 \\
\hline 10 & 1 & 1 & 1 & 88.2114 & 86.6636 \\
\hline 11 & 0 & 0 & 0 & 69.9968 & 71.7653 \\
\hline 12 & 0 & 0 & 0 & 71.1002 & 71.7653 \\
\hline 13 & -1 & 1 & 1 & 58.2776 & 55.3650 \\
\hline 14 & 0 & -1.68179 & 0 & 11.8420 & 12.1786 \\
\hline 15 & -1 & -1 & 1 & 21.7316 & 20.5644 \\
\hline 16 & 0 & 0 & 0 & 72.6508 & 71.7653 \\
\hline 17 & -1 & 1 & -1 & 13.6506 & 14.6440 \\
\hline 18 & 1.68179 & 0.00000 & 0.00000 & 48.2068 & 48.9959 \\
\hline 19 & 0 & 0 & 0 & 70.0178 & 71.7653 \\
\hline 20 & 1 & -1 & -1 & 18.3584 & 19.9619 \\
\hline
\end{tabular}


the value of R2 of 0.9944 , which is very close to 1 , denotes a strong correlation between the observed and the predicted responses. The high value of adjusted coefficient of determination (adj R2 $=98.94 \%$ ) and predicted coefficient of determination (96.84\%) advocates for high

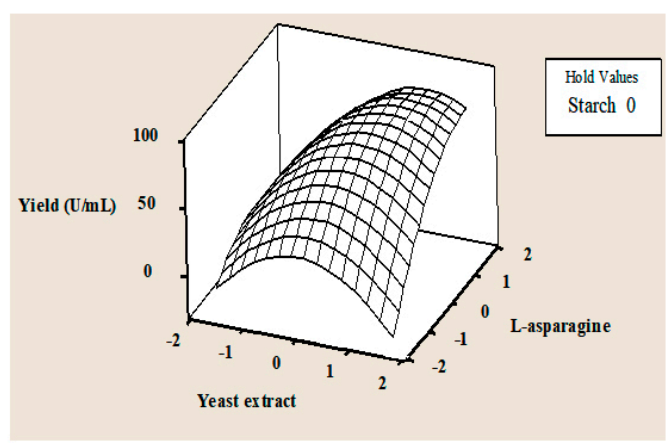

(a)

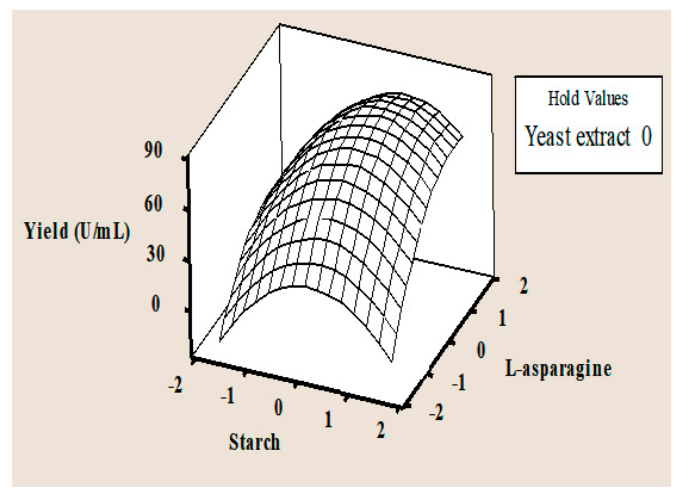

(c)

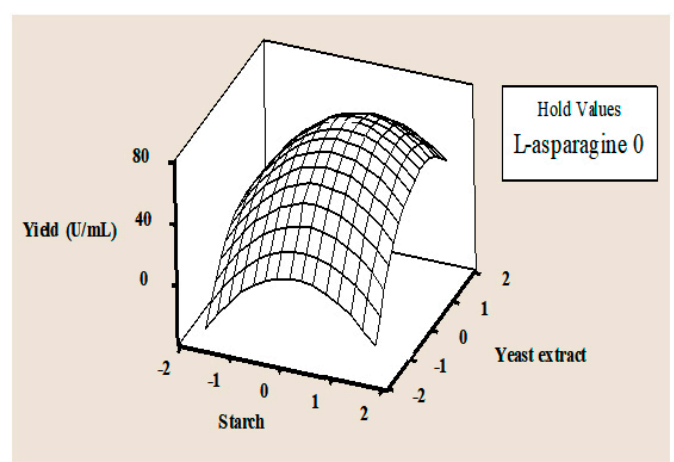

(e) significance of the model. The Lack-of-Fit with F-value of 2.04 and P-value of 0.226 implied that the Lack-of-Fit was insignificant and the model was highly satisfactory.

The significance of the regression coefficients was evaluated by t-test and the

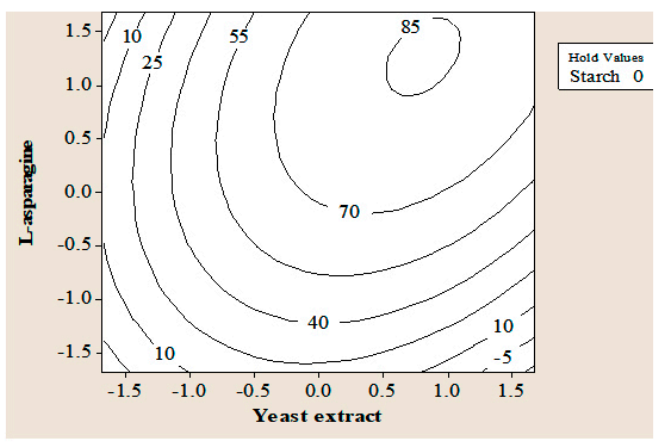

(b)

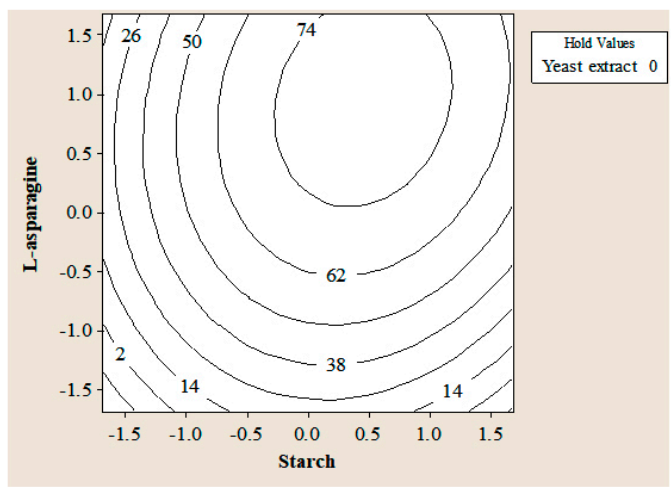

(d)

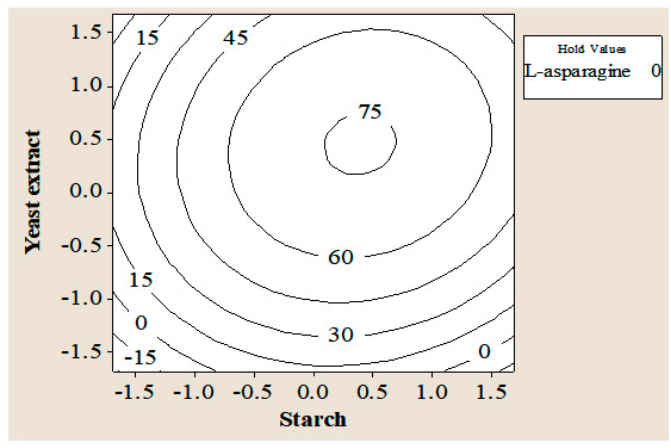

(f)

Fig. 2. Three-dimensional surface plot $(a, c, e)$ and contour plot $(b, d, f)$ of the effect of yeast extract and L-asparagine, starch and L-asparagine, and starch and yeast extract, respectively, on L-asparaginase production by endophytic Talaromyces pinophilus 
P-value. The P-value $<0.01$ denotes the significance of the coefficients and their mutual interactions. This indicates that the combined effects of all the independent variables significantly contributed to maximizing the production of L-asparaginase. The interaction of yeast extract with L-asparagine is highly significant ( $P$-value $=0.000)$. The interaction of L-asparagine with starch is more significant
$(P$-value $=0.004)$ than the interaction between starch and yeast extract ( $P$-value $=0.008)$ on the enzyme production.

The three-dimensional response surface plots were constructed in pair-wise combination for three factors, to predict the L-asparaginase production for different values of the tested variables and to analyze the interactions among

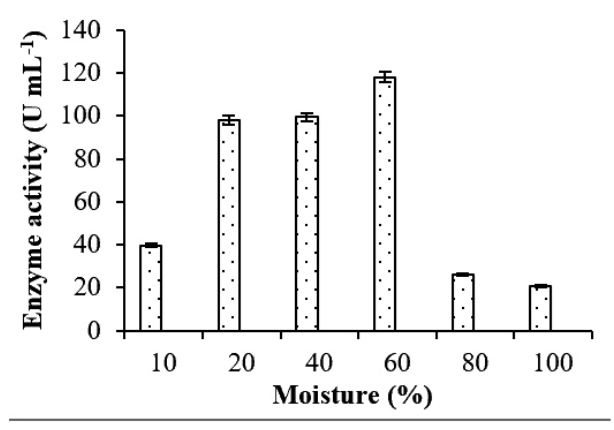

(a)

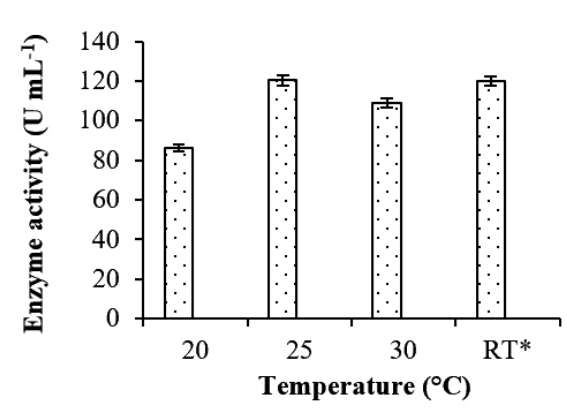

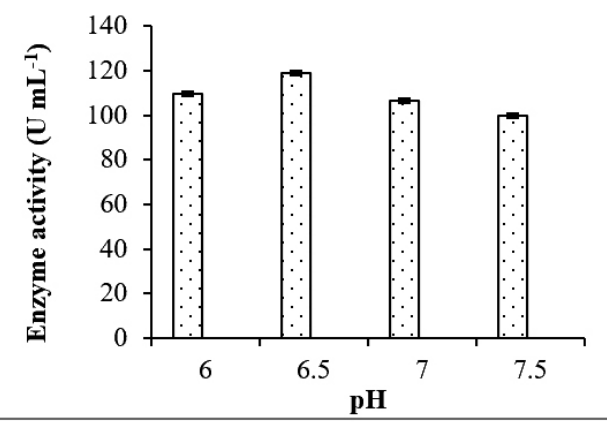

(b)

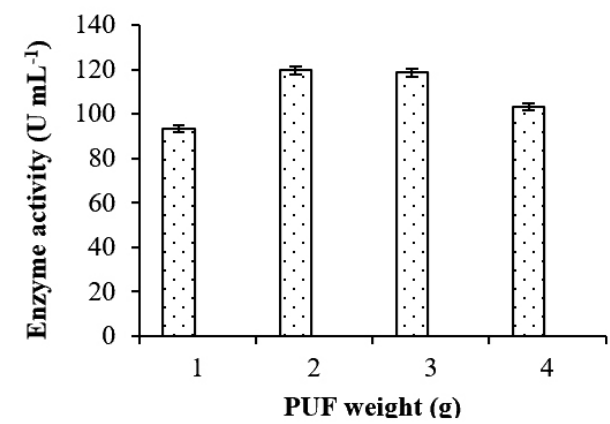

(d)

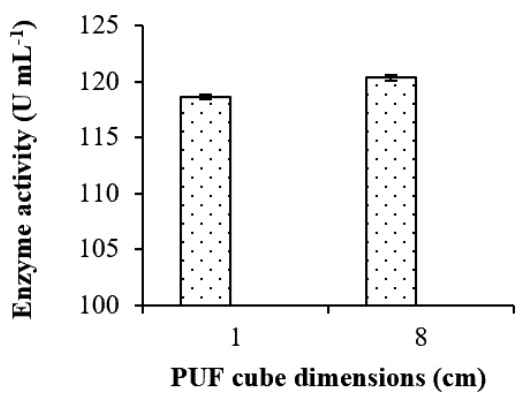

(e)

Fig. 3. Effects of process parameters in SSF: (a) Moisture content, (b) Initial medium pH, (c) Temperature, (d) Mass of PUF cubes, (e) PUF cube volume, on L-asparaginase production. 
the variables (Fig. 2). There was a very good correlation between the experimental and predicted values of L-asparaginase production, since the experimental and predicted values were found to be in close agreement.

The optimal levels of the selected factors (within the design space) were obtained from the optimizer tool. The model predicted a maximum enzyme activity of $91.0 \mathrm{U} / \mathrm{mL}$, with starch, yeast extract and L-asparaginase at optimum levels in coded values (uncoded values in parentheses) 0.6285 (13.143 g/L), $0.9343(14.671 \mathrm{~g} / \mathrm{L})$ and $1.4440(17.220 \mathrm{~g} / \mathrm{L})$ respectively. Upon actual experimentation, the enzyme activity was found to be $91.1 \mathrm{U} / \mathrm{mL}$. This result corroborates the validity and the effectiveness of the model. The desirability of the model was 1.0.

\section{Effect of inorganic salts}

The inorganic salts caused only a slight increase in L-asparaginase production (data not shown). The contribution of individual metal salts towards L-asparaginase production is meagre; but the conjoint action of all the above mentioned metal salts (at such concentrations which appear to have individually caused maximum L-asparaginase activity) when added to the medium optimized by RSM, increased the enzyme activity from $91.1 \mathrm{U} / \mathrm{mL}$ to $93.8 \mathrm{U} / \mathrm{mL}$. The composition of the final optimized media was found to be $(\mathrm{g} / \mathrm{L})$ : Starch, 13.1; Yeast extract, 14.6; L-asparagine, 17.2; $\mathrm{KH}_{2} \mathrm{PO}_{4}, 3.0 ; \mathrm{KCl}, 0.5 ; \mathrm{MgSO}_{4} .7 \mathrm{H}_{2} \mathrm{O}, 0.5$ $\mathrm{FeSO}_{4} \cdot 7 \mathrm{H}_{2} \mathrm{O}, 0.1 ; \mathrm{ZnSO}_{4}, 0.01$.

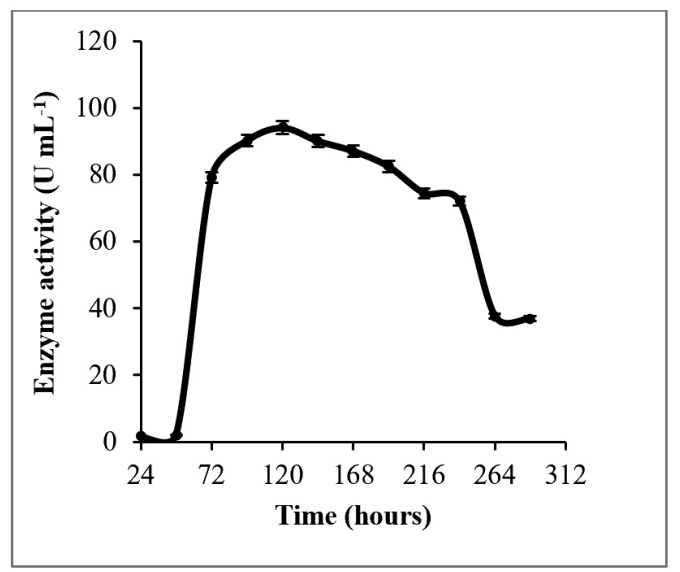

(a)

\section{Solid-state fermentation using PUF: Effect of process parameters}

The density of the PUF was calculated to be $30 \mathrm{~kg} / \mathrm{m}^{3}$, and the maximum water-holding capacity of $8 \mathrm{~cm}^{3}$ PUF cubes was determined to be $7.9 \mathrm{~mL}$, and that of $1 \mathrm{~cm}^{3}$ PUF cubes was 0.89 $\mathrm{mL}$. L-asparaginase production was highest at $60 \%(\mathrm{v} / \mathrm{v})$ moisture content. As observed from Fig. 3a, 10\% moisture is insufficient for enzyme production, while at higher levels of moisture content, the enzyme activity was reduced. In SSF using agricultural residues, the optimum moisture content for L-asparaginase production by non-endophytic fungi lies in the range of $50-70 \%^{9-11}$. Reduction in L-asparaginase activity at low moisture level has also been reported in case of Penicillium sp. under SSF with sugarcane bagasse $^{9}$. The amount of moisture content has to be appropriately chosen to permit accessibility to the nutrients in the media. High moisture percentage can result in low substrate porosity which in turn obstructs oxygen supply, and also can favour bacterial contamination. Low moisture content may lead to poor accessibility of nutrients thereby hindering microbial growth, and may prolong the lag phase of fungi ${ }^{19,20}$.

Initial medium $\mathrm{pH}$ and incubation temperature had a significant effect on enzyme yield. The organism favours $\mathrm{pH} 6.5$ for the enzyme production (Fig. 3b). Initial medium of $\mathrm{pH} 6.5$ has also been reported to be optimum for L-asparaginase production by Aspergillus niger

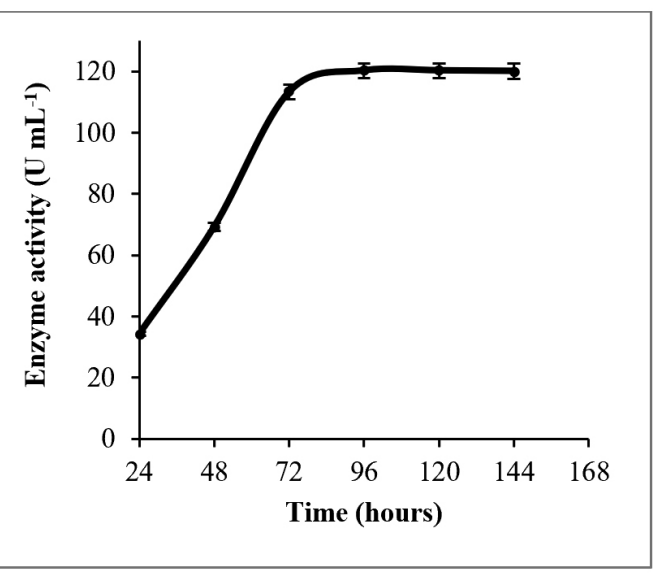

(b)

Fig. 4. Time course of L-asparaginase production in (a) SmF and in (b) SSF 
under SSF using agricultural wastes of leguminous crops $^{11}$. L-asparaginase production was the highest at $25^{\circ} \mathrm{C}$. Even at room temperature (which is bound to fluctuation) the results were equally good (Fig. 3c). The optimum temperature for L-asparaginase production by non-endophytic Penicillium sp.10 and Aspergillus niger ${ }^{11}$ has been reported to be $30^{\circ} \mathrm{C}$ and $40^{\circ} \mathrm{C}$ respectively.

L-asparaginase production was the highest with $2 \mathrm{~g}$ of PUF. (Fig. 3d). As observed from Fig. 3e, there was not much difference in the enzyme production with the cube volumes of $1 \mathrm{~cm}^{3}$ and $8 \mathrm{~cm}^{3}$.

Time course of L-asparaginase production in SmF and SSF

Both in SmF and SSF, enzyme production exponentially increases till about 96 hours (Fig. 4a, b). The highest enzyme production was observed at 96 hours in SSF, and at 120 hours in SmF. The growth curve of certain fungi and L-asparaginase production profile are known to vary with different nutrient sources ${ }^{19,20}$. L-asparaginase production by most non-endophytic fungi is known to peak around 96 hours or beyond ${ }^{21}$. Maximum L-asparaginase production by an endophytic Fusarium sp. is known to occur at 120 hours under $\mathrm{SmF}^{22}$. Highest L-asparaginase production has been reported with 96 hours of incubation, by nonendophytic Penicillium sp. ${ }^{10}$ and Aspergillus niger ${ }^{11}$ under SSF using agricultural wastes. There are also reports on the optimum fermentation time being 72 hours for Bipolaris sp. ${ }^{23}$, or as low as 55 hours for Aspergillus terreus MTCC 1782 under SmF ${ }^{24}$.

Talaromyces pinophilus yielded a maximum enzyme activity of $80.8 \mathrm{U} / \mathrm{mL}$ at 120 hours in liquid MCD medium. Upon optimization of the liquid media, L-asparaginase activity increased to $94.5 \mathrm{U} / \mathrm{mL}$ at 120 hours under SmF. Furthermore, there was about $27 \%$ increase in the enzyme production $(120.3 \mathrm{U} / \mathrm{mL})$ with SSF using PUF soaked in the optimized liquid media. Talaromyces pinophilus seems to favour SSF over $\mathrm{SmF}$, as is the case with most of the fungi ${ }^{13,14,20}$. This increase in the yield might have been due to the usage of PUF in the SSF process, which more closely imitates the conditions under which these endophytes grow in the rhizomes ${ }^{25}$. Moreover, enzyme production by fungi is known to vary in solid and liquid fermentation conditions, as observed in L-asparaginase production from Bipolaris sp. by Lapmak et al. ${ }^{23}$.

\section{CONCLUSION}

The utility of L-asparaginase in therapeutics (as an anti-cancer drug) and in food industry (as an acrylamide-mitigating agent) is noteworthy. Production of L-asparaginase from endophytes can be a promising way to obtain L-asparaginases with different structural, functional and pharmacological properties ${ }^{5,24}$, and also to meet the industrial demand for the enzyme.

The strategy of sequential optimization of the production process, by first designing a suitable liquid nutrient media using SmF, followed by the optimization of the process parameters influencing SSF, is a novel approach. Although there have been reports on the usage of defined media in SSF processes ${ }^{14,16}$, to date, there have been no reports on initial optimization of the liquid media used for SSF. Separately designing the liquid medium simplifies the optimization of the production process through SSF. It also gives a better control over the process, as it is easy to individually assess the influence of the nutrient media and that of the process parameters on the enzyme production. Most of the studies at large carry out optimization of production processes by SmF or by SSF, but not both. Our studies have thrown light on the fact that carrying out SSF with PUF, using the same liquid media optimized for $\mathrm{SmF}$, can enhance the enzyme yield (in our case an increase of about $27 \%$ was observed).

Talaromyces pinophilus isolated from the rhizomes of Curcuma amada produced a high yield of about $120 \mathrm{U} / \mathrm{mL}$ of L-asparaginase, in comparison with L-asparaginase production by certain nonendophytic fungi such as Aspergillus terreus (58 U/ $\mathrm{mL})^{27}$, Bipolaris sp. BR438 $(6.2 \mathrm{U} / \mathrm{mL})^{23}$, Aspergillus terreus MTCC $1782(37.8 \mathrm{U} / \mathrm{mL})^{24}$, Fusarium equiseti $(8.51 \mathrm{U} / \mathrm{mL})^{9}$ and Penicillium sp. (15 U/ $\mathrm{mL})^{10}$. This suggests the capacity of endophytes for large-scale L-asparaginase production, and the feasibility of developing processes for commercial production of the enzyme. However, the adequacy of L-asparaginase from Talaromyces pinophilus for clinical and other industrial applications has to be tested. 


\section{ACKNOWLEDGMENTS}

Prajna Rao Krishnapura was supported by scholarship for doctoral course by the National Institute of Technology Karnataka (N.I.T.K.), Karnataka, India.

\section{CONFLICT OF INTEREST}

The authors declare that there is no conflict of interest.

\section{FUNDING}

This work was supported by National Institute of Technology Karnataka (N.I.T.K.), Karnataka, India.

\section{AUTHORS' CONTRIBUTIONS}

All authors listed have made a substantial, direct and intellectual contribution to the work, and approved it for publication.

\section{DATA AVAILABILITY}

All datasets generated or analyzed during this study are included in the manuscript and/or the Supplementary files.

\section{ETHICS STATEMENT}

This article does not contain any studies with human participants or animals performed by any of the authors.

\section{REFERENCES}

1. Pieters R, Hunger SP, Boos J, Rizzari C, Silverman L, Baruchel $\mathrm{A}, \ldots$ \& Pui $\mathrm{CH}$. L-asparaginase treatment in acute lymphoblastic leukemia: a focus on Erwinia asparaginase. Cancer, 2011; 117(2): 238-249. https:// doi.org/10.1002/cncr.25489

2. Tareke E, Rydberg P, Karlsson P, Eriksson S \& Tornqvist M. Analysis of acrylamide, a carcinogen formed in heated foodstuffs. J. Agr. Food Chem., 2002; 50(17): 4998-5006. https://doi.org/10.1021/jf020302f

3. Crivelari da Cunhaa M, Aguilar JGS, Rodrigues de Melo R, Nagamatsu ST, Alid F, Soares de Castroa, RJ, Satoa HH. Fungal L-asparaginase: Strategies for production and food applications. Food Res. Int., 2019; 126: 108658 (1-10). https://doi.org/10.1016/j. foodres.2019.108658

4. Vimal, A \& Kumar A. I-Asparaginase: a feasible therapeutic molecule for multiple diseases. 3 Biotech., 2018; 8: 278(1-3). https://doi.org/10.1007/s13205018-1282-3

5. Vrooman, LM, Supko JG, Neuberg DS, Asselin BL, Athale UH, Clavell L, ... \& Cohen HJ. Erwinia asparaginase after allergy to $E$. coli asparaginase in children with acute lymphoblastic leukemia. Pediatr. Blood Cancer, 2010;
54(2): 199-205. https://doi.org/10.1002/pbc.22225

6. Muller HJ, Beier R, Loning L, Blutters-Sawatzki R, Dorffel W, Maass E, ... \& Schrappe M. Pharmacokinetics of native Escherichia coli asparaginase (Asparaginase medac) and hypersensitivity reactions in all-bfm 95 reinduction treatment. Brit. J. Haematol., 2001; 114(4): 794-799. https://doi.org/10.1046/j.13652141.2001.03009.x

7. Krishnapura PR \& Belur PD. Partial purification and characterization of L-asparaginase from an endophytic Talaromyces pinophilus isolated from the rhizomes of Curcuma amada. J. Mol. Catal. B: Enzym., 2016; 124: 83-91. https://doi.org/10.1016/j.molcatb.2015.12.007 8. Krishnapura, PR \& Belur PD. Isolation and screening of endophytes from the rhizomes of some zingiberaceae plants for I-asparaginase production. Prep. Biochem. and Biotech., 2016; 46(3): 281-287. https://doi.org/1 $0.1080 / 10826068.2015 .1031385$

9. Hosamani R \& Kaliwal BB. L-asparaginase an anti-tumor agent production by Fusarium equiseti using solid state fermentation. Int. J. Drug Discov., 2011; 3(2): 88-99. https://doi.org/10.9735/0975-4423.3.2.88-99

10. Soniyamby AR, Lalitha S, Praveesh BV \& Priyadarshini V. Isolation, production and anti-tumor activity of L-asparaginase of Penicillium sp. Int. J. Microbiol. Res., 2011; 2(1): 38-42.

11. Mishra A. Production of L-asparaginase, an anticancer agent, from Aspergillus niger using agricultural waste in solid state fermentation. Appl. Biochem. Biotech., 2006; 135(1): 33-42. https://doi.org/10.1385/ ABAB:135:1:33

12. Ooijkaas LP, Weber FJ, Buitelaar RM, Tramper J \& Rinzema A. Defined media and inert supports: their potential as solid-state fermentation production systems. Trends Biotechnol., 2000; 18(8): 356-360. https://doi.org/10.1016/S0167-7799(00)01466-9

13. Zhu Y, Smits JP, Knol W, \& Bol J. A novel solid-state fermentation system using polyurethane foam as inert carrier. Biotechnol. Lett., 1994; 16(6): 643-648. https:// doi.org/10.1007/BF00128615

14. Diaz-Godinez G, Soriano-Santos J, Augur C \& ViniegraGonzalez G. Exopectinases produced by Aspergillus niger in solid-state and submerged fermentation: $A$ comparative study. J. Ind. Microbiol. Biot., 2001; 26(5): 271-275. https://doi.org/10.1038/sj.jim.7000113

15. Hu T, Zhou Y, Dai L, Wang Y, Liu D, Zhang J \& Liu $H$. Enhanced cellulase production by solid state fermentation with polyurethane foam as inert supports. Procedia. Eng., 2011; 18: 335-340. https:// doi.org/10.1016/j.proeng.2011.11.053

16. Rahulan R, Pandey A \& Nampoothiri KM. An improved bioprocess for extracellular L-leucine amino peptidase production using Streptomyces gedanensis. Curr. Microbiol., 2011; 62(3): 1009-1016. https://doi. org/10.1007/s00284-010-9813-0

17. Imada A, Igarasi S, Nakahama K \& Isono M. Asparaginase and glutaminase activities of microorganisms. Microbiol., 1973; 76(1): 85-99. https://doi. org/10.1099/00221287-76-1-85

18. Box E.P.G, Draper K.N. Response surfaces, mixtures and ridge analyses. 2nd ed. John Wiley \& Sons. New Jersey, 2007. https://doi.org/10.1002/0470072768 
19. Del Carmen Marin-Cervantes M, Matsumoto $Y$, Ramirez-Coutino L, Rocha-Pino Z, Viniegra G \& Shirai K. Effect of moisture content in polyurethane foams as support for solid-substrate fermentation of Lecanicillium lecanii on the production profiles of chitinases. Process Biochem.,2008; 43(1): 24-32. https://doi.org/10.1016/j.procbio.2007.10.009

20. Pandey A. Solid-state fermentation. Biochem. Eng J., 2003; 13(2-3): 81-84. https://doi.org/10.1016/S1369703X(02)00121-3

21. Gulati R, Saxena RK \& Gupta R. A rapid plate assay for screening L-asparaginase producing micro-organisms. Lett. Appl. Microbiol., 1997; 24(1): 23-26. https://doi. org/10.1046/j.1472-765X.1997.00331.x

22. Thirunavukkarasu N, Suryanarayanan TS, Murali TS, Ravishankar JP, Gummadi SN. L-asparaginase from marine derived fungal endophytes of seaweeds. Mycosphere., 2011; 2(2): 147-55.

23. Lapmak K, Lumyong $S$, Thongkuntha $S$, Wongputtisin P \& Sardsud U. L-asparaginase production by Bipolaris sp. Br438 isolated from brown rice in Thailand. Chiang Mai. J. Sci., 2010; 37: 160-164.

24. Baskar G \& Renganathan S. Statistical and evolutionary optimisation of operating conditions for enhanced production of fungal L-asparaginase. Chem. Pap., 2011; 65(6): 798-804. https://doi.org/10.2478/s11696-0110072-8

25. Holker U, Hofer M \& Lenz J. Biotechnological advantages of laboratory-scale solid-state fermentation with fungi. Appl. Microbiol. Biotechnol., 2004; 64(2): 175-186. https://doi.org/10.1007/s00253-003-1504-3

26. Krishnapura PR, Belur PD \& Subramanya S. A critical review on properties and applications of microbial L-asparaginases. Crit. Rev. Microbiol., 2016; 42(5): 720-737.

27. Sarquis MIDM, Oliveira EMM, Santos AS \& Costa GLD. Production of L-asparaginase by filamentous fungi. Mem. Inst. Oswaldo. Cruz., 2004; 99(5): 489-492. https://doi.org/10.1590/\$0074-02762004000500005 